\title{
Lisa Hopkins. Renaissance Drama on the Edge. Farnham: Ashgate, 2015. Pp ii, 191.
}

EOIN PRICE

Swansea University
Early Theatre 19.1 (2016), 168-71

http://dx.doi.org/10.12745/et.19.1.2908

In Renaissance Drama on the Edge Lisa Hopkins returns to - but significantly extends - the topic of her earlier book, Shakespeare on the Edge: Border Crossing in the Tragedies and the Henriad (Farnham, 2005). As the titles suggest, this newer book turns towards a wider body of drama than the Shakespearean tragedies and histories that are the subject of the earlier work. But Renaissance Drama on the Edge expands upon the idea of edges in other ways too. Drawing upon her earlier study, Hopkins considers British and French geographic boundaries but also examines an array of different edges, from the material partitioning of walls to the invisible boundaries between heaven and earth. Marshalling a wide variety of non-dramatic material to contextualize her case, Hopkins contends that Renaissance culture 'was both profoundly interested in the idea of edges and borders and also profoundly anxious that all edges and borders were in fact potentially illusory or unstable' (172). In eight chapters, divided into three different sections, Hopkins attends to material and immaterial divisions as they are conceived of in the wider culture of early modern England and in the more specific culture of the commercial playhouses.

The first section, comprising two chapters, is entitled 'What is an Edge?'. The first of these chapters focuses on different ways in which the material division of the wall is represented in plays by Shakespeare and Marlowe; the second examines the invisible border between the secular and the spiritual by reading Shakespeare's plays in the context of Pauline theology. The second section, entitled 'The Edge of the Nation', takes a fresh look at the general subject of Shakespeare on the Edge by considering the complex representations of civic or national borders. Chapter 3 examines cross-border relationships and focuses mainly on British borders as represented by a range of playwrights, while chapters 4 and 5 take as their subjects the southern and northern borders of France in Shakespeare's plays. The book's final section, 'Invisible Edges', features three chapters which meditate on the intersection of the material and the spiritual. In focusing on the Celtic fringe, chapter 6 continues the investigation of national borders undertaken in previous chapters, but it advances into new territory by attending specifically to 'the eschatological charge which may accrue to the edge of Britain' (116) in Renaissance plays. The next chapter approaches the material/spiritual boundary through the ingenious 
idea that jewels might function not only as beautiful adornments but also as extensions of the human body. For Hopkins, Renaissance drama testifies to a surprisingly complex relationship between bodies and material accessories in which jewels have a quasi-magical quality that renders permeable the human boundary of the skin. The final chapter analyzes the divine associations of ruins in plays by Webster and Shakespeare and suggests that such stage locations collapse the divide between the physical and the spiritual.

In her introduction, Hopkins describes her approach as 'eclectic' (7) and cites cultural geography, British/archipelagic studies, and 'the turn to religion' as key influences on her analysis. This varied approach correspondingly requires a wide body of primary material and Hopkins deftly navigates an impressive collection of sources. In addition to plays, Hopkins also discusses early modern historiographical accounts, devotional tracts, prose fiction, and poetry in her bid to reveal the pervasive cultural interest in edges. Indeed, the non-dramatic sources are among the most fascinating aspects of the study: in chapter 3, for example, Hopkins cites an intriguing poem by the Scottish author William Lithgow which reflects upon the morality of the citizens of Berwick-upon-Tweed. These non-dramatic materials are often illuminating and allow Hopkins to make a number of sharp and incisive connections between different plays: in chapter 4 she provides a detailed discussion of the contexts for the naming of Helena in All's Well That Ends Well by addressing a number of accounts of the life of St Helena. Furthermore, the book advances some persuasive readings of individual plays - perhaps especially so in chapter 7 , in which the dual function of jewels is particularly productive and it also makes a number of enlightening dramatic connections. In the first chapter, Hopkins compares Caliban and Coriolanus interestingly; in chapter 5, Soliman and Perseda (attributed to Thomas Kyd) and The Four Prentices of London (by Thomas Heywood) provide useful context for As You Like It.

At times, however, the admirably broad scope threatens to undermine the argument. The book moves quickly — sometimes too quickly — from one point to the next, and this means that some areas feel underdeveloped or unhelpfully gestural. In chapter 1, for example, Hopkins claims that Coriolanus shows 'the edge of the domestic blurring into the edge of the civic' (20), but this implies that the boundaries were not already blurred to begin with: in fact, the domestic was routinely politicized in Renaissance society. The domestic encounter between Coriolanus and Volumnia is an intensely political moment - Volumnia is speaking not only as a mother, but as a representative of Rome - but Hopkins's argument obscures the scene's political charge. Equally, while the range of source material is impressive, the relationship between the theatrical and the non-theatrical is not 
always teased out effectively. In the main Hopkins is content to read the plays for their cultural politics and rhetorical dexterity, but this means that plays risk becoming forms of cultural evidence indistinct from the poems, historical narratives, and theological tracts she cites as contextualizing material. Non-dramatic material is politically complex and often rhetorically skillful, of course, but theatre (depending as it does on some sort of distinction between the staged world and the real world) might be especially well placed to offer new insights into the study of edges. Chapter 8 attempts to acknowledge the particularities of dramatic form by observing how the ephemerality of performance makes the idea of the dramatic ruin more poignant, but the full implications of this interesting claim remain unexplored. Later, the chapter nods its head to the fact that the Blackfriars was a dissolved monastery, but there is no discussion of any of the possible effects this might have had on the theatrical performance of ruins. Chapter 7, interested as it is in props such as rings and in the materiality of skin, might also have benefited from greater attention to the materiality of the theatre.

Yet while the fast pace and wide-ranging approach sometimes pose problems, perhaps the biggest disappointment is the book's comparatively narrow sense of what counts as Renaissance drama. The book does assess some rarely-studied plays and makes interesting connections between canonical and non-canonical texts, but it is surprisingly Shakespeare-centric. Shakespeare features in all of the chapters and he dominates several of them; as the index demonstrates, his name reverberates throughout the book. Certainly Shakespeare has a place - maybe even a prominent place - in the study of Renaissance drama, and attempts to ignore him completely risk endorsing the unfortunate ramifications of the Shakespeare/non-Shakespeare divide, but it is a shame that this book should venerate him at the expense of his less-celebrated contemporaries. When the introduction describes how Shakespeare 'and some other dramatists' (7) found ruins fascinating, Hopkins employs a subtly dismissive tone which does damage to the cause of Renaissance drama. Tellingly, in this locution, only Shakespeare is granted a name. Taken on its own this might be excused as a minor oversight, but the cumulative effect of such oversights serves constantly to cast non-Shakespearean drama as subordinate.

In chapter 2, for example, Hopkins endorses the long established (yet questionable) assessment of Queen's Men's plays as 'crudely anti-clerical' (42), and in chapter 6 she cites John Kirke's The Seven Champions of Christendom, William Rowley's A Shoemaker A Gentleman, and James Shirley's St Patrick for Ireland in relation to Shakespeare only to deride them, in the chapter's evocative final flourish, as 'much cruder' (128) than anything Shakespeare wrote. The reinforcement 
of dated canonical assumptions is all the more disappointing given that the chapter had promised 'to show what Shakespeare does and does not do' (116); instead of finding out that other writers might offer perspectives beyond those available in Shakespearean drama, the conclusion uses the considerable force of its rhetorical weight to denigrate rarely read and rarely studied plays. Hopkins seems happy to suggest that non-canonical plays might illuminate Shakespeare (as in the aforementioned discussion of As You Like It), but it seems to be a one way process: non-canonical plays are rarely allowed to be interesting in and of themselves. Marlowe, Ford, and Webster do receive extended attention, but these writers are canonical in a way that Shirley, Kirke, Heywood, and Rowley are not. They are also usually implicitly (and occasionally explicitly) secondary to Shakespeare in Hopkins's analyses. That it might have been useful to have kept Shakespeare on the periphery of the discussion is suggested by the success of the less Shakespearecentric chapters. In chapter 3, for example, Ford's Perkin Warbeck is paired with Milton's Comus to yield a fascinating reading of cross-border relationships. While the decision to make Shakespeare the sole focus of chapter 2 results in a series of interesting readings of Henry V, Measure for Measure, Julius Caesar, and King John, it feels like overkill to dedicate both of the French chapters to Shakespeare. Indeed, it is a shame that George Chapman - the most French-influenced of all English Renaissance dramatists - should not be mentioned anywhere in the book; after all, Shakespeare was not the only writer to set his plays in the French borderlands.

On the one hand, then, the title of this book is misleading. Despite protestations to the contrary, it is primarily a book about Shakespeare in which some Renaissance dramatists provide additional context. On the other hand, though, the title is oddly, and sadly, appropriate for a book that keeps the wider corpus of Renaissance drama on the edge of the discussion. 